\title{
Experiencing and Learning through Story and Educational Drama: A Workshop Example
}

\author{
Stig A. ERIKSSON \\ Professor Emeritus of Drama Education and Applied Theatre, Faculty of \\ Teacher Education, Arts and Sports, Department of Arts Education, Western \\ Norway University of Applied Sciences, Campus Bergen, Norway \\ stig.audun.eriksson@hvl.no; \\ serikss@outlook.com
}

\begin{abstract}
The article introduces the field of educational drama to new readers by outlining foundational concepts and source literature, and some historical roots. Using the wellknown folk tale of Hansel and Gretel (Brothers Grimm) as point of departure, the article describes a practical workshop example - with a rationale of the suggested activities.
\end{abstract}

\section{Keywords}

educational drama - applied drama - process drama - drama \& folk tale - Hansel and Gretel

\section{Introduction}

Educational drama ${ }^{1}$ have roots reaching as far back as the origins of the Western theatre in ancient Greece (Coggin, 1956; Courtney, 1974; Eriksson, 1979; Bolton, 1998). Already from Aristotle's assertion that 'representation'2 is natural to human beings from childhood and that the human being "learns his first

1 In this context I have chosen to use drama as an umbrella term. It includes the broad field of applied drama and theatre in education. For a further discussion of challenges in relation to uses of Xiju in a Chinese education context, see Zheng Sisi: "Process drama in Chinese education. Possibilities and challenges in governmental policy papers and the curriculum of moral education" (2O21).

2 Greek: mimesis (imitation or representation), which is the essence of 'drama'. 
lessons through representation" (1987, p. 4), drama is explained and situated in a context of aesthetic education. But as a discipline, it has been subject to various degrees of recognition or dismissal in education throughout the ages (op.cit.). Arguments against it, will typically characterise the dramatic medium as an area dealing with the not 'real,' and thus not being serious enough to be accepted as a significant medium of learning. Supporting arguments will, however, emphasise the high degree of concentration and commitment that the dramatic experience can produce, making it real in a heightened sense, by using symbolisation and imagination (Davis, 2014). For those of us, who have practised and researched the field of drama education, drama is not an escape from the practicalities of daily schooling. Drama relates to both significant curriculum matters and what it means to be human (Cziboly/DICE Consortium, 2010) - even if it operates within fictional parameters. In fact, the dramatic fiction's potential to temporarily create a 'bracketing-off' dimension (Bolton, 1984, p. 104, 147), offers a constructive and creative 'distancing' from the immediate real. This dimension, which can also be termed 'aesthetic distancing' (Eriksson, 2009a), makes it possible for participants to experience, explore, investigate and learn about people and events in the real, protected by the imagined real. The following quotes may help illuminating this further:

Dramatic activity is the direct result of the ability to role-play - to want to know how it feels to be in someone else's shoes (HEATHCOTE, 1984, p. 49).

$[\mathrm{T}]$ he immediate power of drama is that it elicits a basic response in both the doer and the watcher to the 'magic' of bringing something into the present and the presence that is not really happening (BOLTON, 1984, p. 147).

In drama we examine actions, attitudes, values and relationships from a dual viewpoint: from the viewpoint of those involved - we 'become' or 'represent' the people in the drama - and also from our own viewpoint as people making, and reflecting on, the drama. So we examine them both 'hot' and 'cold': as participant and as spectator (BYRON, 1986, p. 22).

The dominant prerequisite for creating - or experiencing - a drama is a willingness to accept the dramatic fiction and one's own "role" in it, as an imagined, temporal reality. Drawing on the famous statement by Samuel Coleridge ${ }^{3}$ of what forms an aesthetic response, the British educational drama pioneer, Dorothy Heathcote, considers it as a human instinct to possess "a willing suspension of disbelief" (Heathcote, 1984, p. 82).

3 Biographia Literaria, 1817, ch XIV, p. 145. 
School Drama was a generic educational drama genre in many European countries in the Renaissance and in the Baroque Age, both in Protestant Latin schools ${ }^{4}$ and in Catholic Jesuit schools. It was believed that letting the students take part in theatre performances was a commendable way of learning and practising conversation, eloquence, argumentation and reasoning - a close-to-life kind of education. However, in the wake of Puritanism in the 17th and early 18 th century, in which dramatics of any kind were regarded as potentially sinful activity, dramatic art in school was sustained effectively until the end of the 19th century. From 1900, as a result of the Progressive Education Movement with its child-centeredness and focus on activity learning, and an interest within community centers and organisations in developing theatre for children, drama was reintroduced in schools and communities. In the early pioneering phase, it was primarily practised as dramatization of literature and as speech training (e.g., Harriet Findlay-Johnstone and Elsie Fogerty respectively in the UK in the 1910s) (Bolton, 1998), or as political education (e.g., Bertolt Brecht's learning plays in the 1920/30s in Germany) (Eriksson, 2009a).

Later drama became extended to comprise creativity training and personal development formation, as practised by drama education pioneers before and after the second world war: in the USA (e.g., Winifred Ward, Isabel Burger and Geraldine Brain Siks), in the UK (e.g., Peter Slade and Brian Way), in Sweden (e.g., Elsa Olenius). From around the 1970s, there was a shift towards a more cognitive orientation in drama education, i.e., for exploring knowledge (e.g., Dorothy Heathcote and Gavin Bolton, UK). At the same time, there was also a renewed focus on conventional theatre production and performance skills training (e.g., David Hornbrook, UK), and new forms of critical and explorative educational theatre (e.g., the Theatre-in-Education movement: TIE) (Eriksson, 1979; Bolton, 1998; O'Toole and O'Mara, 2007). By the turn of the present century, drama as an aesthetic education field has a rich assortment of subject literature (scientific as well as practise-based), a selection of international research journals, ${ }^{5}$ several university and teacher education courses worldwide, and an international professional network. ${ }^{6}$

4 As an example - the very first theatre performance that we know of in Norway was in fact a school drama production, a performance of the French Mystery Drama: The play about Adam - performed outside the Cathedral in Bergen in 1562 by pupils from the Latin school.

5 For example: Drama Research (UK); RIDE - Research in Drama Education. The journal of applied theatre and performance (UK); ATR - Applied Theatre Research (AU); NJ - Drama Australia $(A U)$; YTJ - Youth Theatre Journal (USA).

6 Notably: IDEA - International Drama/Theatre and Education Association, and IDIERI International Drama in Education Research Institute. 
After 1900 to the present day, the general historic perspective of trends concerning theoretical justification and practical execution of educational drama, can be roughly described as: 'drama for skills training and performance', 'drama for personal development and creativity training', and 'drama for critical understanding and empowerment. ${ }^{7}$ Keeping these perspectives as reference points in mind, another way of describing drama education is to look at its place and organisation in schools - and even outside schools in the wider community - as an arts education subject in its own right, or as a medium for teaching and learning across the curriculum. It is in the latter mode my practical example of the Hansel and Gretel drama should be understood.

Story as Resource

Hansel and Gretel belongs to the folk tale lore collected by the German brothers Grimm during the first part of the 180os. Like most other folk tales, the story contains themes and motifs that offer a range of interpretations that can be used in a variety of contexts with children - from storytelling in its own right, to dramatization in the kindergarten or the school, to improvised and processual exploration in the form of process drama. ${ }^{8}$ (I shall return to this latter approach below.)

Through centuries, people have told stories reflecting their innermost fears, faiths, desires and dreams - reflecting both individual traits of a particular culture and more universal and recognisable human experiences across cultural borders. Folk tales and other popular story genres represent attempts to interpret human existence, and at the same time to invite searches for moral stance, empathy, understanding, or simply decent comportment. In many cultures, the lore of popular story dissemination has been used through millennia to educate on values, to engage in artistic expression, or to stimulate reflection on contemporary mind and life - and to entertain and be entertained. By their creation of 'wonder' - the immanent aspect of most folk tales - both pedagogues and artists can find educational and artistic inspiration.

7 These perspectives show a similarity with trends in educational theory and practice models: the transmission model, the development model, and the dialogue/critical models (Eriksson, 2009b).

8 Process drama is a contemporary genre of educational drama. It originates from the pioneering work of Heathcote and Bolton but has been further shaped and developed by John O'Toole (1992) and Cecily O'Neill (1995), and many other practitioners in Australia, Canada, UK, USA and the Nordic countries. Chinese readers may also want to consult Heggstad (2019), to learn more about process drama and other educational drama approaches.

9 Like 'wonder tale', from the German 'Wundermärchen' - a term that "embrace both fairy tales and folk tales (Warner, 1995, p. xiv). 
The verb 'to wonder' communicates the receptive state of marvelling as well as the active desire to know, to inquire and as such it defines very well at least two characteristics of the traditional fairy tale: pleasure in the fantastic, curiosity about the real. The dimension of wonder creates a huge theatre of possibility in the stories: anything can happen. This very boundlessness serves the moral purpose of the tales, which is precisely to teach where boundaries lie (WARNER, 1995, p. xvi).

It is this treasure chest of human knowledge and cultural ballast found in folk lore that is on offer as a resource for the teacher of educational drama.

What drama can offer education is a process of learning about complex real-life issues through participants' imagination (Davis, 2014). In the Hansel and Gretel drama example below, the tale is the starting point - even if it is most likely already familiar ${ }^{10}$ to the children. It is also the framework: a frame story of the drama. The carrying pedagogical idea is that when the children are invited to explore different perspectives of the story and to try to solve problems presented in it, they may understand the character's motivations, concerns and needs within the safe confines of the fictional context - provided by the tale on the one hand, and the drama structures on the other. They can experiment with the "what ifs" of the dilemmas inherent in the story.

While the context of a given story may be fantastical, the issues are real, and the problems faced are similar to those of many young readers. The analogies and the metaphors used by the authors of such fiction allow readers safe mirrors in which to examine their concerns. A fictional treatment of a problem with which a reader can identify allows him or her to see it from different viewpoints and to see how someone else might deal with it. The central issue in this type of story must be presented in a way that makes it universal and understandable to a wide range of people (воотн, 1992, р. 18).

From this pedagogical conception of the ' $a$ s if', by the late Canadian story and drama practitioner, David Booth, I have built the ensuing process drama structure of Hansel and Gretel.11

10 Even if some children should not be familiar with the tale, the participants are led step-bystep into the story and kept "protected" by the structuring of the drama.

11 Sur La Lune || Hansel \& Gretel Annotated Tale (surlalunefairytales.com) [Downloaded, 25.02.2021]. 
The genre of process drama must in the present context be understood quite broadly. It is not a given form with a commonly agreed structure or poetics. It is practised in the field of educational drama with a tolerance of personal approach, and choices of form elements and dramaturgy may vary among practitioners according to theme, situation, time frame, aim-group or site. Still, during the international research project DICE (Drama Improves Lisbon Key Competences in Education) in 2010, the following description of key features was attributed to process drama:

Process drama is a genre of educational drama which focuses on collaborative investigation and problem-solving in an imaginary world. Process dramas use 'pre-texts' (stories, photographs, newspaper articles, music, artefacts, etc.) to frame the investigation and raise questions for the students. Process dramas are improvised, not script-based, built up from a series of episodes or scenic units, usually in a non-linear and discontinuous fashion. The entire group of participants are engaged in the same enterprise, and the teacher may function within the drama as playwright and participant ([e.g. teacher-in-role). A primary purpose of process drama is that the participants discover, explore, and articulate a theme, narrative or situation together as percipients, /.../, or put differently: as audience to their own acts. In process drama there is an intention to learn and understand, rather than to perform and entertain (COOPER \& DICE Consortium, 2010, p. 203).

The Hansel and Gretel workshop sample below is presented in notes format; thus it is primarily a description of the structure and main strategies and conventions used. The introduction relates aims and objectives, but otherwise the notes format does not allow for much detail in motivation or evaluation of the choices that make up the workshop. A reflective analysis ${ }^{12}$ of the workshop would need another format, and a collection of research data. So, for this present account, I have to leave it to the readers to try out this structure on their own. The workshop is inspired by process drama literature referenced above, ${ }^{13}$

12 An inspiring book for learning about reflective practitioner analysis is Taylor, Philip (ed.) 1996. Researching Drama and Arts Education: paradigms and possibilities, London: The Falmer Press.

13 An additional recommended source is O'Neill, Cecily (1995). Drama Worlds. A framework for process drama. Portsmouth: $\mathrm{NH}$, Heinemann. This source has recently been translated into Chinese. 
supplemented by the so-called conventions approach (Neelands and Goode, 2000). Uses of still image of various kinds are frequent in the workshop, which is also inspired by the idea of picture theatre (Boal, 1992). I thank my colleague Kari Mjaaland Heggstad for constructive comments in the planning phase.

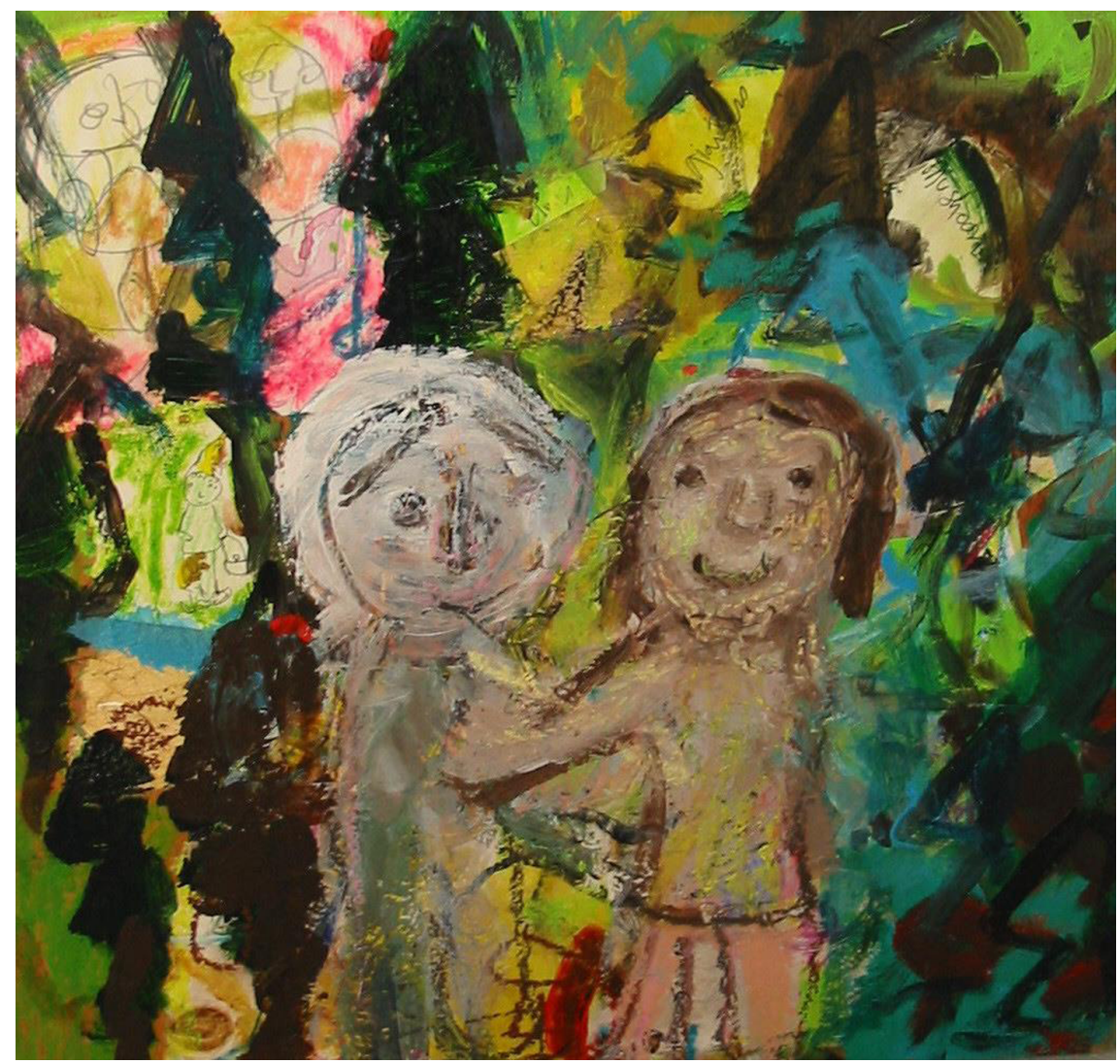

Child art from the Internet. Unknown source. 
HANSEL AND GRETEL. NOTES FOR A Comments and rationale. DRAMA WORKSHOP.

Aims:

Pre-text:

- Show alternative ways into a

The tale is a pre-text for the drama well-known folk tale and explore what can be found "behind" the well-known story.

- Work with and explore aesthetic form via the use of own body, objects, art picture. Give examples of teacher-in-role. Explore significant "moments" in the life of the characters of the story; focus on situation more than outer action; space for reflection.

\section{Rationale:}

Drama in the classroom is primarily about exploring human relations; more than about theatre production or "performance". Drama offers work forms that present possibilities for creative exploration and training in improvisation, spontaneity and imaginative cooperation.

\section{Motives:}

Misery drives poor people's children from home.

The wicked stepmother who banishes the children.

The suppressed husband who fails his responsibility as a parent.

The siblings who do not let each other down.

The evil witch who devours children. The children who fall for the lure.

\section{Creative exploration for both participants and teacher:}

It is an arena for the participants to both investigate and to create. It is also an arena for the teacher to express herself through some supplementary pedagogical registers.

\section{Terms from literary analysis:}

In pre-planning the educational possibilities of the fairy tale, it may be helpful for the teacher to make use of elements from literary analysis, like theme (the basic idea) and motif (stock situations). Here are some possibilities from the Hansel and Gretel story: 
HANSEL AND GRETEL. NOTES FOR A Comments and rationale.

DRAMA WORKSHOP.

\section{Themes:}

Absence of care.

The fear of being abandoned.

Evil can be overcome.

Love (between siblings) prevails.

The contrast between the good and the evil in the world.

Heroism.

The drama structure:

\section{Warming up.}

(a) "Red light"-game: The whole group at the back of the room. A volunteer in the other end of the room, facing the wall. Counts to 10 , shouts "red light", whilst turning to check on the group who has been moving forward during the count. If anyone is caught making a move, she has to get back and start again. Whoever gets to the volunteer's position first, is the winner. (I will return to the structure of this game later, when Gretel steals the keys of the witch).
Suggestions. Not all ideas need to be used:

Game structure.

Not in itself drama. The intention is primarily to get the group "started". Concentration on individual task, yet with an awareness of others. 
HANSEL AND GRETEL. NOTES FOR A Comments and rationale. DRAMA WORKSHOP.

(b) Circle of statues. Everyone in a circle, facing outwards. When the leader's call for a statue is heard, everyone immediately shapes herself into the named statue, and turns inwards as the statue. "Without changing your position, try to get an impression of other statues in this moment". Positions are kept until the leader gives another key word for a statue. Key words: Father, mother, stepmother, witch, pathfinder, loneliness, evil, love, hero. Leader asks participants to try to remember some of the hero-positions 'for later'.

- Tell the story. Circle. Each one tells one little part of the Hansel and Gretel fairy tale as they remember it, and in such a way that something is left of the story for the last person too. A white pebble stone is passed from one narrator to the next around in the circle, as symbol and as a marker of turn. Ritual. "Tell your part with a serious attitude; don't worry if you don't remember everything "correctly"; this is not a memory contest; you can even say "pass" if you get a black-out. Pass the stone to the next in the circle when you finish your part of the tale".

\section{Still image:}

Spontaneous creative response.

Participants frequently present statues that may contain an element of cliché. No problem! Clichés often contain an element of truth.

\section{Alternatively:}

The teacher may take on the responsibility to tell the story. This alternative gives the teacher better control of the timing and that all significant moments are told. It is fine to present an abridged version. 
HANSEL AND GRETEL. NOTES FOR A Comments and rationale. DRAMA WORKSHOP.

- Aims. Teacher briefly imparts the Explanation of what and why: aims of the drama structure. See the Depending on the aim group. introduction above.

- Images. The group is divided into Group work. subgroups of 5 participants.

(a) Theme: Each group makes a pic- Still image/tableaux: ture (tableau) entitled: Hansel \& The images impart information. Gretel. Similar or different themes emerge?

(b) The home: With masking tape, teacher marks on the floor the Marking the space: outer area of the house they live in, whilst checking out with the group about size and form. Then the rooms are taped up and some 'furniture', too.

(c) Everyday moments: Plenary. At the home of Hansel and Gretel. Starting point is one of the group pictures from (a). Collective image-creation without words. Stylisation rather than realism. Only one participant at the time can make a change in the positions/relations in the Hansel \& Gretel image. What changes take place? What do these moments tell us about their life?

Still image in transformation:

Working collectively, in silence, creates tension and concentration. Breeds focus on content, and elicits awareness of form. 
HANSEL AND GRETEL. NOTES FOR A Comments and rationale. DRAMA WORKSHOP.

(d) The portrait on the wall: Pairs in turn they shape each other into a portrait of: (i) The children's own mother, now dead.

(ii) The children's stepmother. Volunteers enter the house; present the versions they have helped each other to create. (Teacher has an empty picture frame which she holds up in front of the face of mother and stepmother during presentation. The audience close their eyes before presenting each portrait).

(e) The family picture: How does the stepmother prefer that the family looks like in the eyes of others? The family's "image".

- Teacher-in-role (TiR) as the father. Needs advice. Participants are his wood cutter colleagues. Situation: that there is only a half loaf left to share. The wife has demanded that the children must leave.

\section{- Parents quarrelling: Participants} place themselves on the parameters of the house. They are the 4 walls. Teacher: "Once there was happiness and laugher in this house, but no more".

\section{Portraits in contrast:}

The presentation should be given a quality of performance. "Photo" exhibition of two mothers.

An image of façade.

TiR as family provider:

Represents a figure with an attitude and a sentiment. TiR should not be a character but show a dilemma.

The walls have mouth and ears: This convention is the frame for both (a), (b) and (c). It includes the whole class (= the walls) and creates a collective focus. It is important to create the walls with straight lines; everyone facing inwards; observing the modelling sequences in silence but can provide advice when asked. 
HANSEL AND GRETEL. NOTES FOR A Comments and rationale. DRAMA WORKSHOP.

(a) Teacher models two participants to represent the parents quarrelling in one room. Checking with the main group about possible adjustments.

(b) Two participants are Hansel and Gretel in their beds in the neighbouring room. Volunteers model them first. The children will hear their parents quarrelling.

(c) Teacher: "The quarrel resonates in the walls. The walls know the arguments, because the walls have heard the quarrelling before. Let us hear the parents' quarrel through the walls".

Teacher starts as the father: "I don't think that I can do it".

- Group sculpture. Two half groups, one for Hansel and one for Gretel. Each group sculptures a dream picture that Hansel and Gretel see this night after the quarrel. Those who were Hansel and Gretel in the previous sequence (b) create (one each) the initial dream sculpture with the bodies of the others.

Modifications by moving in and out in turn. "What kind of dream pictures did we get?"

- Art picture.

(a) Groups of four. Each group gets an art picture. It is Hansel and Gretel. (See illustration above). "Where in the story are they?"
The father/mother and the Hansel/ Gretel models do not speak, but can react in their positions. It is the walls that perform the quarrel.

\section{Dreams:}

The dream images offer a way of conceptualising family tensions in a contained and aesthetic form; not teacher-directed but with a possibility to invite discussion.

\section{Using other art forms:}


HANSEL AND GRETEL. NOTES FOR A Comments and rationale. DRAMA WORKSHOP.

(b) Then in pairs: They take/copy the positions of the figures. Let it be a moment of significance. What thoughts/reflections do the figures have? Music: Philip Glass and Foday Musa Suso, "Leila Dies". (Music from The Screens, 1992). Volunteers show their pictures in the circle. We will hear the thoughts of $H \& G$ when the leader puts her hand on their shoulder.

- The wandering. Participants in two rows form a winding path in the room. They are the trees in the forest. Two volunteer participants are Hansel and Gretel.

Teacher narrates: "Hansel and Gretel walk through the forest on way to their unknown destiny, and the forest whisper and make noises while they are walking. Each time the children bend down to look for a berry, they get to hear the wisdom of the forest. The forest may try to scare them, but together they find courage in walking on, listening to sounds and utterances. Music: Glass and Suso,"The Orchard". (Music from The Screens, 1992).

- Brief discussion about experiences so far. Then short break.
In this sequence, visual art and music are used to provide other stimuli to enrich the experience. My selections here are of course subjective and can be replaced.

Thought tracking.

The forest can speak:

Both these conventions offer protection for the participants, through aesthetic form, to voice thoughts, concerns, opinions. 
HANSEL AND GRETEL. NOTES FOR A Comments and rationale. DRAMA WORKSHOP.

- Pair work. Hansel and Gretel sharing the loaf by the camp fire. What do they talk about? Two rows with some distance between the pairs. Improvisation scene. Constraint: Each of them is sad and without hope, but both tries to conceal that from the other. Hansel utters the first remark.

Teacher: "We can 'listen in' to their conversation. They are mostly whispering, but their talk becomes lauder, for everyone to hear, whenever I touch one of them on the shoulder".

- Creating the witch's house. Teacher tapes on the floor the outer area of the witch's house, whilst checking out with the group about size and form. Teacher asks which main rooms and which main "furnishing" are needed? Where is the cage? Where is the oven? Where is the main door?

- Role modelling. Collective sculpturing of the witch as a seducer by the entrance. One volunteer is the witch.

- Verse. In pairs write a 4-liner verse which is her allurement formula. The pairs find a way of performing them, but each pair has to start from the position of the sculpture.

\section{Imaginary objects.}

'The loaf' and 'the bonfire' must be established. Each pair decides on a way to make it 'real' for them.

Whenever they are ready, Hansel will start the conversation, for example: 'How do you feel now?'.

\section{Participants' contribution:}

Participants get ownership of the space by being invited to 'create' the house of the witch. And a sense of safety and commitment when allowed to model the witch.

Creative writing: 
HANSEL AND GRETEL. NOTES FOR A Comments and rationale. DRAMA WORKSHOP.

- The recipe. All in a circle. Teacher-in-role as the witch reading from her book the best recipe for a children's meal. The evil ritual. Each participant comes forward and contributes to the recipe with an ingredient and puts it in the "cauldron".

The witch starts: "An apple first. The green side for Hansel, the red side for Gretel. To be dripped around the stem are two drops of sweat from my own forehead"...

- Stealing the witch's keys. Plenary. Try to make this happen through the initial "red light" game structure. The volunteer is on a chair as the witch, the keys lying on the floor between her feet. She drowses off $5^{-10}$ secs. (counts) at the time. The big group are the animals of the forest, trying to help Gretel to retrieve the keys to the cage where Hansel is locked up. They all "freeze" each time the witch looks up, but if caught, they "die" on the ground. (If the venture fails, we must accept that, but we can still be at liberty to decide that even if the witch was on the alert and stopped the animals from getting the keys, Gretel in the end managed to get the keys and to free Hansel).
Composing the witch's allurement formula (and charm objects), and the witch's recipe works in a similar way and builds belief in the fiction. It is probably fun and exciting, too.

An agreement as to where "the cauldron" is must be established before the witch starts.

\section{Game structure.}

The well-known children's game: "Stealing the King's keys" is transformed to fit the present drama structure. 
HANSEL AND GRETEL. NOTES FOR A Comments and rationale. DRAMA WORKSHOP.

- The witch's death. The teacher narrates how Gretel outwitted the witch. (Improvise from what happened above in the game). Teacher asks some volunteers to enter the circle and show their hero statues from the beginning of the workshop. "Can you select one of them to represent Gretel?"

- Gretel as the hero of the story. Teacher invites each participant to formulate a statement which can stand as a judgement of Gretel's action - a kind of "people's judge-

Hero statues.

Paying tribute to Gretel's cunning by individual statements, brings us back to the starting point, but now filled with retrospective reflections ment". It may also be good to briefly on the action.

tell the end of the story, and that also the stepmother is now dead.

- The wicked stepmother on the chair. (The teacher in role). Participants (in a half circle facing her) are collectively Hansel and Gretel. They interrogate the stepmother about her action.

- The father's letter to the children. Creative writing. Participants imagine that the father Reflection mood. writes a letter to his children, that he hopes they will find some day... Each one writes their own letter.

- Final discussion. "What have we explored beyond the tale of Hansel and Gretel"? Start with the considerations of motif and theme from the frame in the first part of this document. Any relevance to our own time and experience?

\section{Hot-seat.}

Being on the hot seat can be demanding and is in this context best to be left to the teacher.

\section{Contemporary relevance?}

$-$

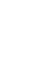


"My tale is done, there runs a mouse, whosoever catches it, may make himself a big fur cap out of it".

I can best end this article by the final words above by the tale's teller, apparently the Grimm brothers, who collected it. Although this workshop structure with most, if not all the episodes - has been tried out and worked in as different countries as Norway, Croatia, China and Turkey, I have not yet researched the reception of it beyond the level of general feedback. For the present context, I have added the column of pedagogical rationale and meta comments. My intention has been to introduce new readers to educational drama by offering a hands-on example. The idea of example [Latin: exemplum] has a rich tradition in rhetorics and in educational literature. This example is my offer to others to try to catch it and make something out of it.

\section{References}

Aristotle (1987). Poetics (translated by Richard Janko). Indianapolis, Indiana: Hackett Publishing Company.

Boal, Augusto 1992. Games for Actors and Non-Actors. New York: Routledge.

Bolton, Gavin (1984). Drama as Education. An argument for placing drama at the centre of the curriculum. Harlow: Longman.

Bolton, Gavin (1998). Acting in Classroom Drama. A Critical Analysis. Stoke on Trent: Trentham Books/University of Central England.

Booth, David W. (1992). Censorship Goes to School. Markham, Ontario: Pembroke.

Byron, Ken (1986). Drama in the English Classroom. London: Methuen.

Coggin, Philip A. (1956). Drama and Education. An Historical survey from Ancient Greece to the present day, London: Thames and Hudson.

Cooper, Chris (ed.) \& DICE Consortium. (2010). Making a World of Difference. DICE resource for practitioners on educational theatre and drama, Budapest: DICE Consortium. http://www.dramanetwork.eu/file/Education\%2oResource\%2olong. pdf.

Courtney, Richard ([1968] 1974). Play, Drama \& Thought. The Intellectual Background to Drama in Education. London: Cassel \& Co.

Cziboly, Ádám (ed.) \& DICE Consortium DICE Consortium (2010). The DICE has been cast. A DICE resource. Research findings and recommendations on educational theatre and drama, Budapest: DICE Consortium. http://www.dramanetwork.eu/file/Policy\%2O Paper\%2olong.pdf. 
Davis, David (2014). Imagining the Real. Towards a new theory of drama in education, London: Institute of Education Press/Trentham Books.

Eriksson, Stig A. (1979). Drama as Education. A descriptive study of its development in education and theatre with particular relevance to the U.S.A. and England, Calgary, Alberta: University of Calgary. https://1drv.ms/b/s!AjebEkgsYsIlhdgKPIy7hwxwq6I $\mathrm{mRw} ? \mathrm{e}=\mathrm{yF}$ WWSY.

Eriksson, Stig A. (2009a). Distancing at Close Range. Investigating the Significance of Distancing in Drama Education. Vasa: Åbo Akademi University. https://1drv. ms/b/s!AjebEkgsYsIlhdgLQCdwOrzVijnAlg?e=fKfBx2.

Eriksson, Stig A. (2009b). Looking at the Past for Stepping into the Future: Background reflections for Drama in the Curriculum of the $21^{\text {st }}$ Century. In Jack Shu and Phoebe Chan (eds.). Planting Trees of Drama with Global Vision in Local Knowledge, Hong Kong: IDEA Publications and TEFo.

Hansel and Gretel. Annotated Tale. Sur La Lune || Hansel \& Gretel Annotated Tale (surlalunefairytales.com).

Heathcote, Dorothy ([1972] 1984). Drama as challenge. In Johnson, Liz and O'Neill, Cecily (eds.). Dorothy Heathcote: Collected writings on education and drama. London: Hutchinson \& Co.

Heggstad, Kari Mjaaland (2019). Tongwang Jiaoyu Xiju De Qitiao Lujing, Shanghai: ECNU Press Ltd. Translator: Maja-Stina Johansson Wang, Zhi Wang, Yuk-lan Phoebe, Sisi Zheng. [This is a Chinese, revised version of the Norwegian book: 7 veier til drama. Grunnbok i dramapedagogikk for leerere i barnehage og skole].

Neelands, Jonothan and Goode, Tony (200o). Structuring Drama Work. A handbook of available forms in theatre and drama. Cambridge: Cambridge University Press.

O'Neill, Cecily (1995). Drama Worlds. A framework for process drama, Portsmouth, NH: Heinemann. Chinese edition: O'Neill, Cecily (2020). Xiju de Shijie: Guocheng Xiju Sheji Shouce. (Yiwen Ou, Trans.). Xinbei Shi: Psychological Publishing.

O'Toole, John (1992). The Process of Drama. Negotiating art and meaning, London: Routledge.

O'Toole, John and O'Mara, Jo (2007). Proteus, the Giant at the Door: Drama and Theater in the Curriculum. In L. Bresler (ed.). International handbook of research in arts education. Dordrecht: Springer.

Warner, Marina (1995). From the Beast to the Blonde. On Fairy Tales and their Tellers, London: Vintage.

Zheng, Sisi (2021). Process drama in Chinese education. Possibilities and challenges in governmental policy papers and the curriculum of moral education, Applied Theatre Research, Vol. 9, No. 2. 